\title{
Human reliability in petrochemical industry: an action research
}

\author{
João Alexandre Pinheiro Silva ${ }^{\mathrm{a}, \mathrm{b}^{*}}$ and João Alberto Camarotto ${ }^{\mathrm{b}}$ \\ ${ }^{a}$ Production Engineering Department, ESEG, R. Vergueiro, 1951, São Paulo, Brazil \\ b Production Engineering Department, UFSCar, Rod Washington Luiz Km235, São Carlos, Brazil
}

\begin{abstract}
This paper aims to identify conflicts and gaps between the operators' strategies and actions and the organizational managerial approach for human reliability. In order to achieve these goals, the research approach adopted encompasses literature review, mixing action research methodology and Ergonomic Workplace Analysis in field research. The result suggests that the studied company has a classical and mechanistic point of view focusing on error identification and building barriers through procedures, checklists and other prescription alternatives to improve performance in reliability area. However, it was evident the fundamental role of the worker as an agent of maintenance and construction of system reliability during the action research cycle.
\end{abstract}

Keywords: Human Reliability, Error Identification, Ergonomic Workplace Analysis, Resilience engineering.

\section{Introduction}

The restructuring of production processes throughout the entire petrochemical chain brought impacts on the labor division, resulting in a series of new demands for knowledge and skills, which are added to old ones, in order to maintain the reliability of the production system.

The objective of this paper is to build a theoretical framework on human reliability and ergonomics as well as the observation and analysis of an oil refinery production system. It aims to identify conflicts and gaps between the strategies and actions developed by the operators as system reliability maintaining agents in their work daily routine, and the organizational managerial approach for human reliability in the company.

In order to achieve these goals, the research approach adopted encompasses literature review, mixing action research methodology and Ergonomic Workplace Analysis in field research. The studied company is a Brazilian private and capital intensive firm. It belongs to the chemical and petrochemical industry.
This paper is organized as follows. Section 2 presents the literature review. The methodological aspects of the field research are presented in Section 3. Section 4 presents the results and discussion. Finally, Section 5 includes the conclusions.

\section{Literature review}

\subsection{Human reliability}

The literature review identified 304 articles about human reliability, of which only 50 items are classified in the field of ergonomics. The major research stream on human reliability focuses on nominal scenarios and assessment instruments, and therefore, in the ergonomics point of view, focuses on the task, i.e., the prescribed work [1-5]. Another research stream is focused on the real work analysis as well as psychological and cognitive aspects [6-11]. More recently, a third stream emerged which discusses human reliability according to resilience engineering point of view [12-14].

\footnotetext{
Corresponding author. E-mail: xanpinheiro@dep.ufscar.br
} 


\subsection{Ergonomic Workplace Analysis}

One of the pillars in this study is the Ergonomic Work Analysis (EWA), which seeks answers to the emerging demands within the productive situations, taking as its focus the work activity $[8,15]$.

According to Guérin [15], the AET bases on four grounds: the distinction between task and activity; concept of variability, the concept of workload and the concept of operating mode.

The first ground relates to the distinction between task and activity. The task is what is prescribed by the company and the operator and is not the work, while work activity is an adaptation strategy of the operator to the real work situation, the object of the prescription. Thus, Guérin [15] reasons that the ergonomic analysis of the activity is the analysis of the strategies used by the operator to manage the gap between prescribed and real work, i.e., the analysis of human-system task.

The second foundation is the concept of variability, associated with what was not expected and manifested in productive situations. Thus between task and activity there is the imponderable, and it is important to understand how workers cope with the diversity and variations of situations and what consequences they result on health and production. Thus, the variability implies in the need to recognize the implicit instability in man-work system.

Ergonomics classifies variability in two: subject variability and company variability [16]

The concept of workload is divided into both physical and mental portion, the last one subdivided into cognitive and emotional. The workload is a synthesis of the confrontation of two conditions, the task in the company's perspective and the activity in the worker's perspective, which results returns on both employee and company. For the employee, the workload is expressed on their health, while for the company the load impacts the production and productivity [15].

The fourth ground of AET is the concept of operating mode, which distinguishes different ways for performing the same task. It is important to notice that this concept comes from earlier concepts and represents the individual response to the determinants of a work situation.

In view of a given context, in which the goals are set and means available, the subject produces a representation of the situation, and builds its operative mode. The choice by the subject of a specific operating mode is derived from the possibilities of regulating both activity and competence. Moreover, the variability bring to work characteristics from each particular moment and the workers make use of the available means or invent other ways to perform their activities, thus enabling visibility to regulation strategies [16].

Concluding that the effectiveness of the work does not come from mere respect to prescriptions, but the ability to regulate the activity performed by the acting subjects, managing the changes in activity and its effects..

\section{Research methodology}

A methodological approach of action research was adopted due to the need for intense involvement of the researcher with the groups of operators and technicians who will be the subject of field study. A dynamic interaction throughout the research project will be vital as the theoretical framework can be designed, developed and analyzed. As a result, it requires the researcher a privileged access to all key-persons in the organization who have some kind of involvement with the studied situation, and they recognize the value and usefulness of action research in progress.

It is necessary to emphasize that, in the action research methodology in addition to the formulation of a problem, it is taken into account the proposal of a suggestion or solution for the question under study, that both researcher and client cooperate in developing a diagnosis and scientific solution for a problem, which contributes to the stock of knowledge in a particular field [17].

Studies highlight that, in general, the researcher acts as an outside facilitator in the action of the company or group of companies, allowing then to reflect and analyze independently [18]. Thus, it is important that the researcher is used to systematically record their observations and experiences, which helps in building the knowledge from important events.

Being a very dynamic approach, Coughlan and Coghlan [18] suggest that action research happens in cycles consisting of three distinct phases. The first phase is the pre-analysis, which defines the context and purpose. The development phase consists of six sequential steps. The monitoring phase is the metastep process that feeds the other steps, it is a key step and it is primarily to the researcher. It is the construction of knowledge stage. Several cycles of action research are possible, which creates the opportunity for continuous learning. 
As mentioned before, the purpose of this paper is to study the human reliability in view of ergonomics and therefore from its methodological approach.

According to Wisner [19], the originated ergonomic methodology in the analysis of work has diversified and consolidated with a considerable body of research and studies, highlighting the main aspects:

- Extension of environmental analysis, adding demographic, biological and anthropological aspects;

- Methodology of work activity analysis;

- Methodology of solution preparation, above recommendations;

- Extension and deepening of the criteria for successful intervention.

It is necessary to highlight the importance of studying the environment, in regard to the economic, social, demographic and anthropological aspects, as fundamental in ergonomic analysis [19]. Thus, the emphasis that prevailed on job analysis and the recommendations and suggestions for improvements, focusing on individual workstations and ergonomic aspects of computer systems work, has expanded to form a new field of ergonomics concerned with the role of workers within organizations and formed a third generation of ergonomics.

Thus, the action research approach brings up several synergistic aspects to the Ergonomic Analysis of Work $[8,9]$.

The approach used in this analysis focuses on the very activity of the worker and the pursuit of understanding of this activity performed in order to satisfy the demands in their jobs, along with both observation and effect indication that the interaction with actual factors in their work situation (physical environment and organizational factors) have on these employees, the performance of their activity and aspects of human reliability in interaction with their equipment and artifacts.

Given the methodological options for the research, it was necessary to find an organization that would allow the involvement of the researcher, as well as privileged access to key persons in the organization in the area of reliability, to workers and the environment in organizational analysis. Based on these requirements, the study was conducted in a large refinery in the period from 2008 to 2010.

For two years the researchers spent an average of eight hours a week involved in the studied environment. It was allowed access to 13 area operators and 4 shift supervisors, weekly, and the 3 engineers in charge of reliability, always in scheduled meetings.
In addition to direct contact with those involved, multiple sources of evidence from secondary data were collected such as document analysis, procedures, rules and policies of the studied organization, primary data collection through analysis of the physical environment, measurements, photos and videos, interviews, meetings and workshops.

\section{Results}

\subsection{The studied company}

According to the Petroleum Intelligence Weekly, the studied company is among the ten biggest companies in the downstream sector - refining, transportation and marketing. The term downstream is connected to a great deal of the operational structure of the studied company, consisting of fourteen factories in Brazil, the United States and Argentina. In Brazil there are eleven refineries with capacity to produce 1.986 million bpd, two fertilizer plants, a shale plant, totalizing $31,089 \mathrm{~km}$ of pipelines, 44 terminals, bases and 50 ships (own fleet).

The company constantly improves its downstream activities, seeking to meet the growing domestic market for derivatives, the requirements for fuel quality, man safety, the possibilities of export and care for the environment.

The Company has undergone therefore a profound restructuring of the company's manufacturing processes under review, with different impacts on the content of the work throughout the process due to different ages and technological complexity in each production facility, located in different areas of the country. This restructuring process has impacted the division of labor, the demand for knowledge and skills and required behaviors from the operators.

The field research was developed in one of the studied company's eleven refineries. This unit of analysis will be renamed Refinery.

Special attention has been given to the need in readjusting the dashboard of a turbo pump, implanted in the refinery's production line during automation process and the change to a Digitized Distributed Control System (DCS), as it motivates the consideration of how equipment design and implementation of technological innovations on the production line have been performed.

The research was developed in the midst of implementing a program of ergonomic action that includes aspects of information management, human 
reliability analysis, personal injury, design of work environments and worker training.

\subsection{Human Reliability in Enterprise}

What is the vision of the studied company about human reliability?

Through analysis of operational standards, the managerial standards and internal security manuals, as well as document survey released to employees and presented in events on the topic of human reliability, it is possible to have a reference and interpret how this vision is structured within the organization.

From this interpretation it is possible to estimate the dominant conception in the Company regarding human reliability among schools and trends already presented and relate it to one of the given types of approach for the management of human reliability, and thus guide the researcher's focus on identifying the actual elements in work situation related to aspects of human reliability, during the monitoring of operational activities, for the analysis of the operator in the industrial area at the time of application of the methodology of ergonomic work analysis.

The following seeks to draw a profile on human reliability management, contextualizing from some collected sections and evidences, which are cited and commented.

A formal definition of human reliability is presented in a corporative manual distributed to employees participating in training on reliability conducted by the company, as follows:

- What is human reliability?

- A way to define it is simply as the probability that a task or service is successful within the time set aside for it. Human error can be defined as failure of planned actions to achieve the intended goals ... It is during the implementation or control of a task or service that the error occurs. Importantly, it occurs inevitably in the hands of the factory floor workers (operators), not directly in the hands of managers and executives. (Riskless Operations Manual, Enterprise Edition).

In another section of the same book, with a focus on equipment reliability, it is found an explicit understanding of what is human error and its importance for the reliability:

- In fact, one might say that up to $90 \%$ of all equipment failures can be attributed in one way or another to human error. For example, if after making an excellent project, a proper manufacturing, test execution and approval by the Quality Control of the equipment in question, that is, most efforts aiming at reliability have been directed to the machines and to components, not to taking into account human error, and leaving room for at least $50 \%$ reduction in the efficiency of the used system.

Even when taken into account the possibility of a failure by interference from other present elements in the system, a complex relationship between factors such as environment, organization, information, training, planning and projects lead to accidents and crashes. It is clear in the following excerpt also the predominant classical mechanistic technical rationality and the kind of vision of the human being as an agent of unreliability (when referring to the inefficiency of the barriers):

- The inevitable tendency to error stems from the limited capacity of human memory, the limit in information processing and / or dependence of specific rules for the task.

The intolerant environment does not allow the operator to receive feedback in time for him to take measures to prevent the transformation of the error or defect. Often it is not even possible the immediate perception of error. "The absence of barriers between the error and failure and the impossibility of error recovery feature an intolerant environment."

Other excerpt shows the same mechanistic aspects of the human blame, as follows:

- The top management, supervisors and workers in general must accept their responsibility for errors. Knowing how to do things properly is an exemplary goal.

- The engineering know-how is not enough for the tasks to be properly performed by people, it is necessary to know the management system and its functions, its principles, and especially a lot of experience in the behavioral sciences and the "human engineering".

The choice of a management system with a compartmentalized view of the management of human reliability, based on the belief that it is through the perfect prescription patterns and planning the task, you get the best result, as suggested by the following excerpt:

- If the actions do not occur as planned, planning was inadequate.

- Experience shows us that human beings can perform such activities as an individual system in a 
suitable environment and be self-sufficient for a long time...

- The main objective to be achieved is to create the best possible match between people and machines within the system constraints. A complete machine one would offer a great bond with the man.

What is evident in events organized by the company and its manuals, in more than one of their business units, is the manifestation of the company in understanding the human reliability supported by pillars: management, procedures, equipment, environment and interactions (see Figure 1).

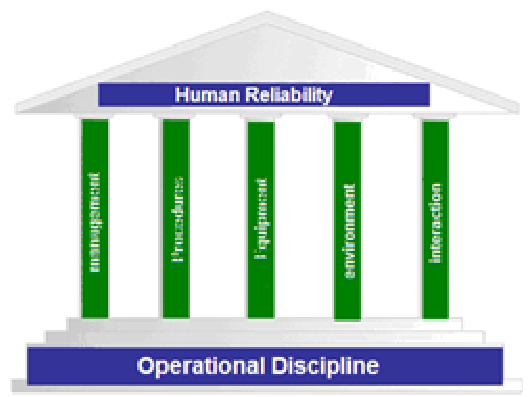

Figure 1 - Operational Discipline Campaign

Source: Presentation at the internal seminar on human reliability of the Company.

It can be seen in Figure 1, the base supporting this structure is operational discipline. In this sense the campaign has intensified operational discipline in the company.

The basis of human reliability on the operational discipline, in compartmentalized way, as submitted by the Company in Figure 1, reflects the weight of the so-called "human errors" as the main cause of variations and / or malfunctioning, and the search for restricting them through management and preparation of task requirements, through the construction of standard procedures, directed by the concepts of redundancy, diversification, quality of equipment, mainly in the design of situations.

It also presents a prescriptive view in perspective of a strict failure control, where human beings are characterized as agents of unreliability, sources of errors, adjustments classified as violations or nonconformities.

The concept of human reliability in the studied company, explicit rules, procedures and other internal documents, as presented in section 3.3.5, provides a classical mechanistic technical rationality, in line with the definitions of $[25,26]$, in which the human being is seen as an agent of unreliability.

The situation presented is characterized, among other factors, as a collective work, which involves processing technologies of dangerous products, with high cognitive load [21, 22]. Always present are, therefore, the physical, cognitive and psychological components $[8,23]$.

In these situations, in which professionals rely on remote collaboration, communication is essential at work. Communication is not the means of performing the tasks, it represents the core activity. Communication is recognized as a value in these situations, and even a good value: it has a cost, but also productivity.

The way of work organization based on new information technologies and forms of process control away from the workplace, makes the quality of communications among members of a collective, critical to the quality of the performed work. Through the performed analysis, it has been observed that the field communication is between the field operators via radio, during situations of monitoring activity, and that equipment malfunction a constant, be it by defects of the equipment or by battery. The type of used equipment requires the lateral tilt of the cervical spine so that the operator can better hear the broadcasts. This situation is aggravated by high intensity noise present in the area, without forgetting the proper use of hearing protection. There was also a vibrant exchange and systematization of information in the local control house, which supplies, in many ways, the gaps between the prescribed and real work.

Additionally, there are several arising problems from the adaptation of the population, to technology, ranging from the need for translation of English terms to semantic issues related to several concepts that are reflected in the confused interpretation of light signals. Several of these issues could have been minimized if the prerequisite of the ergonomic study, as suggested by Wisner (1991), had been done when the introduction of DCS.

There are some inconsistencies and incompatibilities in the interpretation of concepts and terms, and indication of equipment. They are different among administrators; operators and administrators (see Figure 2).

Some examples found in the analysis were the concepts of instrument-equipment critical system and instrument-equipment complex system. Administrators and operators have different concepts about the purpose and occasion of interpretation and application of this term, the goals and direct actions on 
equipment and systems so classified. There is also the trivialization of the signs of criticality, which leads to the perception that everything is critical, which is by itself a perversion of this concept.
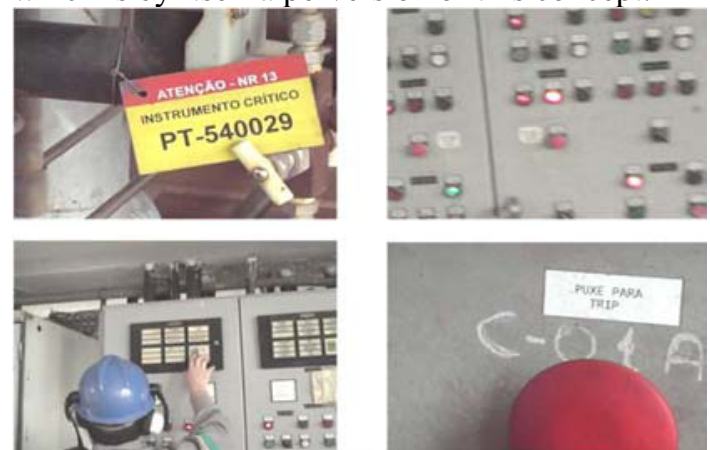

Figure 2 - Concepts of signs and colors.

Another mentioned conflict is the signaling by red and green colors with different types of interpretation, it is equipment or pendant that is active or stopped, blocked or available. The accumulation of indications of different equipment in different situations (green and / or red) on the same instrumentation dashboard with on and out lights on local and remote control devices on the same dashboard.

These instructions call for the reading of information of various types on the same dashboard and require constant alertness, performance and judging by the operator for information processing and its significance, and the construction of their own forms of signaling through multiple labels, and signs written on equipment.

The activity of surveillance and control of instruments, constantly exercised by the operator, aims to act quickly before the occurrence of abnormalities.

According to the examined literature in situations of reliability and safety risk as the studied, the formulation, transmission, the information and instruction comprehension are crucial. The clarity, evidence, data accuracy are critical to interpretation and reaction to system changes. On the other hand, the action of man within these complex systems is essential, as already evidenced by several authors [26, 27] , and also found in the analyzed context, where the operator is responsible for making choices and making decisions, gathering information, sometimes in adverse situations at work, as presented in this analysis.

In the industrial area, as well as on the dashboard and on the body of the turbo pump, viewing displays of various instruments is affected by the illumination of the site, for display maintenance, positioning problems of the display for the reading. Notes aid infor- mation is checked on various targets. Are also present written information in English, accumulation of instructions on the sequence of operations and maneuvers, which are attached on the body or around the equipment. Presence of information in the body of the panel or equipment that do not relate directly to the routine work of the operator or the operation of the equipment (see Figure 3).
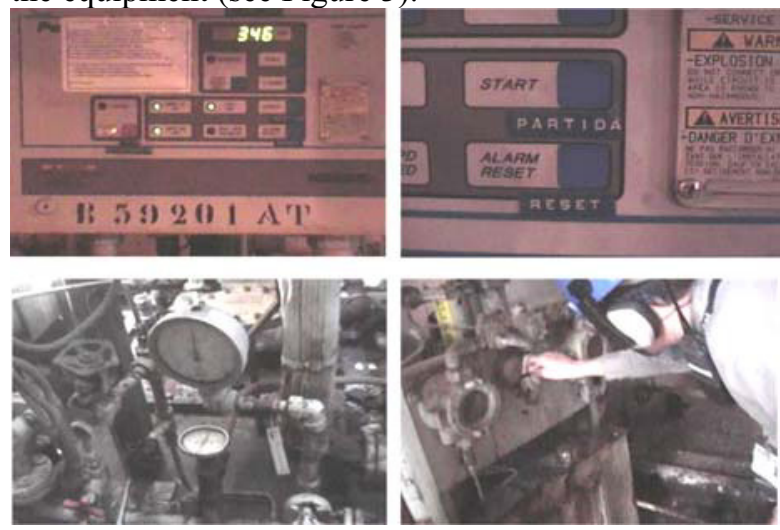

Figure 3 - Problems of clarity, evidence and accuracy of the information

Operators create true systems for information records and reporting to meet the performance of their duties and the communication needs that they perceive in their activity and are not available because were not formally planned or are insufficient.

These record systems are distributed in the industrial area in the form of notes in the body of equipment, paper with diagrams, tables of information, and different denominations of equipment (see Figure 4).
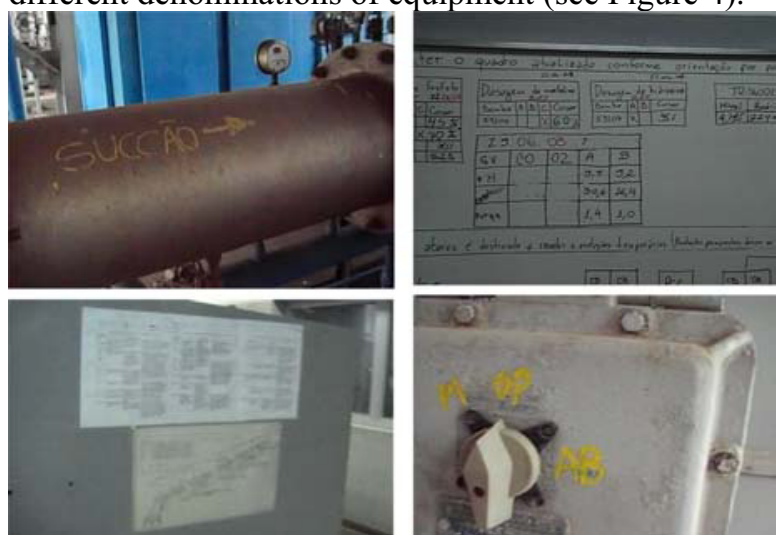

Figure 4 - Systems and information used by operators

During the monitoring of the operator routine, it has been found that the variability and complexity of the process, the presence of colors and shapes of 
flags, which require interpretation as to its meaning and validity, require the establishment by the operator of various systems of "redundancy "information, i.e., after reading an indicator instrument the operator evaluates through another information parameter by their abilities and senses like vision or touch, for comparison with the instruments.

It is configured with this feature the support to decision and actions on complementary and not contradictory information, and that such mistrust in the instrument plays a key role in the safety process, particularly when it comes to facilities with a low degree of reliability.

The checklists emphasize the nominal scenario, major criticism to the methods of evaluation of reliability, according to various authors $[4,5,28]$.

The tool for the parameter annotation of the equipment, checklist, does not distinguish them by need or importance, there is a uniform list of presentation data with little room for notes and observations of the potential operator (see Figure 5). The manipulation of the checklist is a constant problem to be solved by the operator for transportation, registration and preservation of information of its annotations in the industrial area.

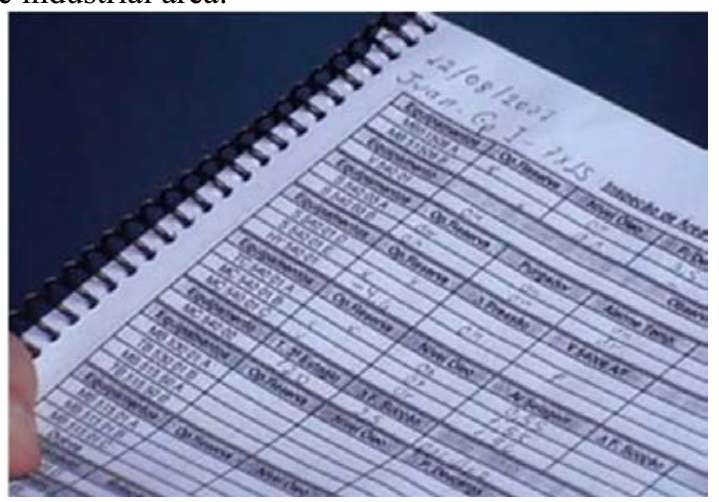

Figure 5 - Checklist used by operators.

The concept shared by the operators of the meaning of each piece of information is that it guarantees and justifies the decisions for actions to be performed, that is what ensures a coordination of individual and collective actions in the resolutions of new and complex problems that can occur daily. The common concept of the meaning of information is part of building an overall picture of the state of the system by collective bargaining.

The gap between the prescribed and actual work is significant and requires a significant cognitive effort by operators to overcome adversity encountered in the task. There are many strategies adopted by opera- tors to mitigate these gaps in practice, individual and collective, through intense communication and adoption of integrated actions. In this sense, traders are agents of reliability, because it makes possible to control the possible fluctuations of systems through the variability of reactions [6]

Usually these procedures, as noted above, are rarely considered by management that, in general, perceives as unwarranted expressions of resistance to change, especially during the implementation of automated systems [30].

\section{Conclusions}

The studied company has classical and mechanistic point of view focusing on the errors identification and construction barriers through procedures, checklists and other prescription alternatives to improve performance in reliability area, i.e., aligned with the literature stream focus on nominal scenarios, quantification techniques and reliability assessments, and therefore, strong aligned industrial engineering perspective on human reliability, exemplified by Kirwan approach [31-33]. Thus, in ergonomics point of view theses researches focuses on the task in the prescribed work [9].

However, it was evident the fundamental role of the worker as an agent of maintenance and construction of system reliability during the action research cycle. There are several strategies adopted by operators to mitigate, in practice, the gap between prescribed and real work. Thus, the second and third research streams seem to be helpful to better understand the real work analysis concerning reliability issues.

The second objective way to investigate the reliability of management prescribed by the studied company, it has established some aspects already mentioned in the analysis of the theoretical framework. The first observation is that the studied company has a classical mechanistic view [23, 24], the predominant view in literature too. The Company focuses its operations in the area of reliability in the identification of errors and construction barriers through procedures, checklists and other alternatives to prescription.

The type of management is the top-down, focusing on technology, without the participation of future users, creating inconsistency between perspectives and real results. As suggested by the literature, it has become clear that there is a gap between the actual 
work carried out by the operation and the perception by the management of the same work [34].

In addition, the company sees the worker as an agent of unreliability, with their tendency to blame.

Nevertheless, the role of the worker as an agent of maintenance and construction of elements of system reliability (the third objective of this dissertation). There are many strategies adopted by operators to mitigate in practice the gaps between prescribed and real work, whether in isolation or collectively. In this sense, the approach is that operators are agents of reliability $[6,29]$.

The workers' effort to mitigate these gaps enhance their physical, cognitive and psychological load, catalyzed by the complexity and danger of the analyzed system $[8,21,22,23]$, and this gap results still in a negative impact on the stability of the system as reliable, which can only be remedied with the effective participation of workers in the process of innovation, transformation and management of reliability.

\section{References}

[1] Kirwan, B; Scannali, S, Robinson, L. A Case Study of a Human Reliability Assessment for an Existing Nuclear Power Plant. Applied Ergonomics, v. 27, n. 5, p. 289-302, Oct 1996.

[2] Kirwan, B, Kennedy, R, Tayloradams, S, Lambert, B. The Validation of Three Human Reliability Quantification Techniques - THERP, Heart And Jhedi.2. Results of Validation Exercise. Applied Ergonomics, v. 28, n. 1, p. 17-25, Feb 1997.

[3] Shorrock, St, Kirwan, B. Development and Application of a Human Error Identification Tool For Air Traffic Control. Applied Ergonomics, v.33, n. 4, p. 319-336, 2002.

[4] Mosleh, A; Chang, Yh. Model-based human reliability analysis: prospects and requirements. Reliability Engineering \& System Safety, v. 83, n.2, p. 241-253, 2004.

[5] Bertolini, M. Assessment of Human Reliability Factors: A Fuzzy Cognitive Maps Approach. International Journal of Industrial ergonomics, v. 37, n. 5, p. 405-413, May 2007.

[6] Faverge, J.M. L'homme, agent de d'infiabilité et de fiabilité du processus industriel. Ergonomics, v.13, n.3, p.301-327, 1970.

[7] De Keyser, V; Vandaele, A. Human Reliability, Safety, Automatization - Study of Operators on Manual Command Lathe and Computer Numerically Controlled Lathe. Travail Humain, v. 49, n. 2, p. 117-135, Jun 1986 .

[8] Wisner, A. Por Dentro do Trabalho: ergonomia, método e técnica. São Paulo: F.T.D., 1987.

[9] Guérin, F. Laville,A.; Daniellou, F. Comprendre le travail pour le transformer, la practique de l'ergonomie. Montrouge, Ed. Anact, 1991.

[10] Wilson, Jr. Devolving Ergonomics - The Key to Ergonomics Management Programs. Ergonomics, v. 37, n. 4, p. 579594, Apr 1994.

[11] Amalberti, R. Da gestão dos erros à gestão dos riscos. In FALZON, P. Ergonomia, Ed Blucher, 2007, capítulo 17, p. 235-247.
[12] Shorrock, St; Kirwan, B, Mackendrick, H, Kennedy, R. Assessing Human Error In Air Traffic Management Systems Design: Methodological Issues. Travail Humain v. 64, n. 3, p. 269-289, Sep 2001

[13] Wreathall, J. Properties of Resilient Organizations. In Hollnagel E., Woods D., Leveson N. (Eds.) Resilience Engineering, USA: Ashgate Publishing, 2006.

[14] Wilson, Jr; Ryan, B; Schock, A; Ferreira, P; Smith, S; Pitsopoulos, J. Understanding safety and production risks in rail engineering planning and protection. Ergonomics. v. 52, n.7, p. 774-790, 2009.

[15] Guérin, F.; Laville,A.; Daniellou, F. Compreender o Trabalho para Transformá-lo, a prática da ergonomia. Ed Edgard Blucher, 2004.

[16]Dejours, C. Por um Trabalho, Fator de Equilíbrio. Revista de Administração de Empresas. São Paulo, Mai./Jun, 1993.

[17] Bryman, A. Research methods and organization studies. London: Unwin Hyman, London, 1989. 283 p.

[18]Coughlan, P; Coghlan, D. Action research for operations management. International Journal of Operations \& Production Management. v. 22, n. 2, p. 220-240, 2002.

[19] Wisner, A. A inteligência no trabalho: textos selecionados de ergonomia. São Paulo. FUNDACENTRO, 1994.

[20] Wisner, A. Antropotecnologia: coletânea de textos. Revista Ação Ergonômica, ABERGO, v. 1, 1991.

[21] Perrow, C. Normal accidents; living with high-risk technologies. New York, basic books, 1984a.

[22] Perrow, C, Complexity, coupling and catastrophe. New York, USA, Basic Books Pub. 1984b.

[23] Gaillard, A. W. K. Comparing the concepts of mental load and stress. Ergonomics, v.36, n. 9, p. 991-1005, 1993.

[24] Rook, L.W. Reduction of human error in industrial production. No $^{\circ}$ Report STCM, 93-62, 14. Sandia Corporation. 1962.

[25] Swain, A D \& Guttmann, H. E. Handbook of Human Reliability Analysis with Emphasis on Nuclear Power Plant Applications. US Nuclear Regulatory Commission. Washington, 1983.

[26]Dekker, S, Ten questions about human error - a new view of human factors and system safety, Lawrence Erlbaum Associates, Taylor \& Francis Group, 2005.

[27] Crandall, B., Klein, G., Hoffman, R, Working minds: a practitioner's guide to cognitive task analysis, The MIT Press, Cambridge, Massachusetts, 2006.

[28]Reer, B. Review of advances in human reliability analysis of errors of commission, Part 1: EOC Identification. Reliability Engineering and System Safety, v. 93, n. 8, p. $1091-1104$, 2008.

[29]Ferreira, L.L; Iguti, A.M. O Trabalho dos Petroleiros: perigoso, complexo, contínuo, coletivo. Ed. Scritta, São Paulo, 1996.

[30] Kirwan,B. Human Error Identification in Human Reliabili-ty Assessment.1. Overview of Approaches. Applied Ergonomics, 23(5):299-318,1992a.

[31] Kirwan, B, Human Error Identification in Human Reliability Assessment.2. Detailed Comparison of Techniques. Applied Ergonomics, v.23, n.6, p. 371-381, 1992b.

[32] Kirwan,B. The Validation of Three Human Reliability Quantification Techniques THERP,HEART and JHEDI.1. Technique Descriptions and Validation Issues. Applied Ergonomics, 27(6):359-373,1996.

[33] Garrigou A., Daniellou F., Carballeda G., Ruaud S., Activity Analysis in Participatory Design and Analysis of Participatory Design Activity, International Journal of Industrial Ergonomics, v. 15, 1995. 